\title{
The Dresden Predictor Study of anxiety and depression: objectives, design, and methods
}

\author{
Julia Trumpf • Noortje Vriends · Andrea H. Meyer • \\ Eni S. Becker · Simon-Peter Neumer · \\ Jürgen Margraf
}

Received: 11 February 2009/Accepted: 19 August 2009/Published online: 3 September 2009

(C) Springer-Verlag 2009

\begin{abstract}
Objective The present report describes the objectives, design, and methods of the Dresden Predictor Study (DPS) of anxiety and depression, a prospective epidemiological study investigating anxiety disorders and depression in 3,065 young German women (18-25 years of age).

Materials and methods The DPS consists of a baseline and one follow-up investigation separated by approximately 17 months. At both time points, respondents were diagnosed according to the Diagnostic and Statistical Manual of Mental Disorders, 4th Edition (DSM-IV) using an extended German version of the Anxiety Disorders Interview Schedule (ADIS-IV-L). In addition to diagnostic assessment, respondents completed a battery of self-report questionnaires that provided detailed information about potential predictors of disorders and a comprehensive dimensional assessment of psychopathology.
\end{abstract}

J. Trumpf $(\bowtie) \cdot$ N. Vriends $\cdot$ J. Margraf

Faculty of Psychology, Department of Clinical Psychology

and Psychotherapy, University of Basel,

Missionsstrasse 60/62, 4055 Basel, Switzerland

e-mail: julia.trumpf@unibas.ch

\section{A. H. Meyer}

Division of Applied Statistics in Life Sciences, Department of Clinical Psychology and Psychotherapy,

Faculty of Psychology, University of Basel,

Missionsstrasse 60/62, 4055 Basel, Switzerland

\section{E. S. Becker}

Clinical Psychology, Behavioural Science Institute,

Radboud University Nijmegen, P.O. Box 9104,

6500 HE Nijmegen, The Netherlands

\section{S.-P. Neumer}

Centre for Child and Adolescent Mental Health,

P.O. Box 4623 Nydalen, 0405 Oslo, Norway
Discussion and conclusions Results on both response bias in the baseline investigation and effects of dropout at follow-up are presented, and strengths and limitations of the study design are discussed.

Keywords Epidemiology - Prospective longitudinal . Community study $\cdot$ Anxiety $\cdot$ Depression

\section{Introduction}

Anxiety disorders and depression are the most prevalent mental disorders in the adult population. Prevalence rates in women now double those in men [7, 32]. In order to better understand, treat, and prevent anxiety disorders and depression, prospective community studies examining potential predictors of the incidence and outcome of these disorders are essential $[35,36]$. This community-based research is particularly important because epidemiological samples are less likely to be affected by the effects of selfselection, treatment and help-seeking bias, and therefore, data arising from these studies are probably more representative for the general population. The present report describes the objectives, design, and methods of the Dresden Predictor Study (DPS) of anxiety and depression. The DPS is the first prospective epidemiological study in former East Germany to investigate the prevalence, incidence, and predictors of anxiety disorders and depression in women aged 18-25.

Most major epidemiological investigations of anxiety disorders and depression utilizing the Diagnostic and Statistical Manual of Mental Disorders (DSM)-III-R or DSM-IV criteria are prevalence studies [2, 28, 32, 33, 46], while prospective studies are scarce $[6,38,61]$. One large study in The Netherlands examined anxiety disorders and 
depression in an adult community sample and found that the incidence rate of anxiety disorders per 100 person-years at risk was 4.56 for women and 1.62 for men; major depression had a similar high incidence rate of 3.90 for women and 1.72 for men [6]. In a community study of American high school students (9-12 graders), $7.14 \%$ of the women and $4.35 \%$ of the men developed an incident major depression during a 12-month period. Incident anxiety disorders were less common in this young sample: only $0.84 \%$ of female students and $0.30 \%$ of male students developed an anxiety disorder [38]. Using a German sample of somewhat older participants (aged 14-24), another study reported that $15.84 \%$ of women and $7.45 \%$ of men experienced the incidence of an anxiety disorder during 4 years. For any depressive disorder, the incidence was $13.24 \%$ for women and $7.39 \%$ for men [8].

One finding reported consistently across all studies is that both participants' gender and age influence incidence rates of anxiety disorders and depression. Incidence rates are approximately twice as high in women as in men. Also, studies conducted with a higher proportion of young adults report higher incidence rates [8, 38]. The available epidemiological studies still have some limitations. Only one of the previous studies assessed disorders using the definitions and diagnostic criteria of the DSM-IV [8, 61]. Two of these studies had the added problem of investigating participants in an either very young (15-18 years) [38] or unrestricted age range (18 years and older) [6] even though the peak risk period for developing anxiety disorders and depression is limited to early adulthood [32]. Moreover, most of the available prospective community studies assessed a very small number of potential predictors of these disorders.

Summarizing from previous studies, it would be important to study a broad range of predictors of anxiety disorders and depression during the developmental phase in which these disorders occur for the first time. Given the high prevalence and incidence rates of anxiety disorders and depression in women, studying predictors in women during early adulthood would be important. In this context, the German Ministry of Science, Research and Education funded the DPS [42]. The DPS has four major objectives:

1. Identification of potential predictors of the incidence of anxiety disorders and depression in young women. The DPS aims to study predictors of both dimensional measures and categorical diagnosis of psychopathology. The term "predictor" refers to factors that temporarily precede changes in mental health status $[35,36]$. The DPS aims to study a broad range of categorical and dimensional predictors, assessed by means of a diagnostic interview and self-report questionnaires.
2. Identification of potential predictors of remission in anxiety disorders and depression.

3. Examination of a variety of both pathogenetic and salutogenetic factors known or hypothesized to be related to anxiety disorders and depression. The DPS aims to investigate both categorical and dimensional measures of these factors.

4. Estimation of prevalence, incidence, and remission rates of anxiety disorders and depression as well as examination of comorbidity of these disorders with each other.

A further related objective is to study correlates and consequences of anxiety disorders and depression. Also, the DPS aims to provide basic information needed for the development of effective preventive programs and the improvement of intervention measures for anxiety disorders and depression.

\section{Study design}

The DPS has a prospective longitudinal design based on a random general population sample of German women living in Dresden (the capital city of the federal state of Saxony) and aged 18-25 years at initial assessment. This age range was chosen because early adulthood is the peak period for first onset of many mental disorders, especially anxiety disorders and depression [32]. To ensure that a sufficiently high incidence rate was attained, the sample was restricted to women, having a twofold elevation in prevalence and incidence rates of anxiety disorders and depression [6].

A graphical representation of the overall study design is depicted in Fig. 1. The DPS consisted of a baseline investigation conducted from July 1996 to September 1997, and one follow-up from December 1997 to February 1999. The time interval between baseline and follow-up was approximately 17 months $(M=16.9$ months, $\mathrm{SD}=$ 6.0 , range $=7-30$ months). Due to the large number of participants, it was technically not feasible to maintain a constant time interval between baseline and follow-up. At both time points, respondents completed a structured diagnostic interview and a comprehensive battery of selfreport questionnaires. Baseline interviews assessed 7-day and lifetime information; follow-up interviews also assessed 7-day information plus the time interval since baseline. If respondents declined the face-to-face interview they could choose to complete the questionnaires only. Respondents who refused to participate in the study were asked to complete a short questionnaire asking for basic information about mental problems. Participants were free to refuse to participate entirely. 


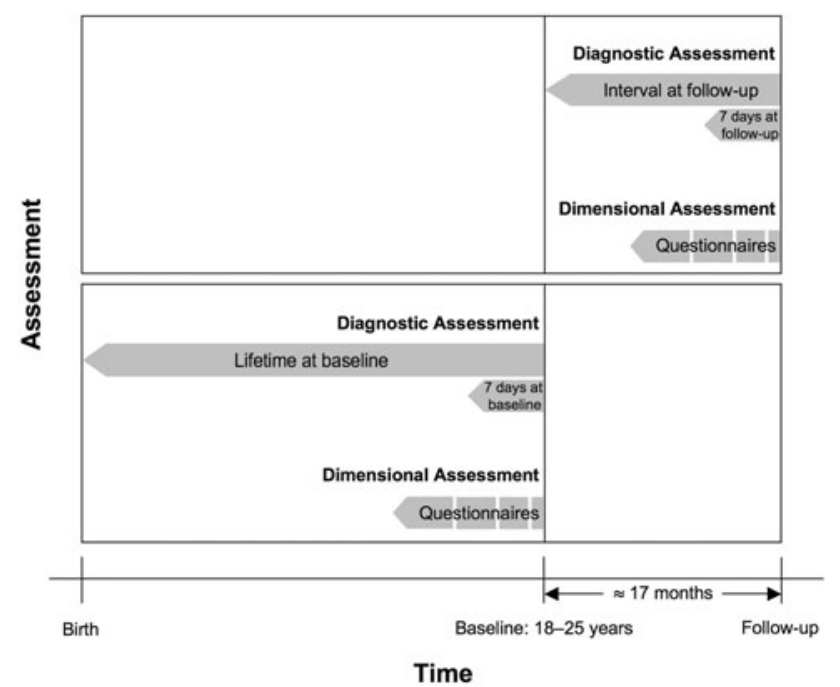

Fig. 1 Overall design of the Dresden Predictor Study

\section{Sample}

Sampling procedure and baseline investigation

The DPS is based on an unweighted random sampling procedure. The baseline sample was drawn randomly in April 1996 from the representative registers of the government registry office in Dresden. In Germany, these registers are supposed to include all residents because every person is obliged to register. All respondents had to meet selection criteria of being female and being 1825 years of age at the time of the baseline investigation. According to the Dresden communal statistical office, the total number of residents in Dresden on December 31st 1996 was 456,102. Of the total population in Dresden, $52.1 \%$ were women and the total number of women aged 18-25 years was estimated to be 18,830 ( $4.1 \%$ of the total population or $7.9 \%$ of the population of women) [58].

A total of 9,000 addresses were drawn randomly from the Dresden government registry of residents in 1996. From these, 3,797 (42.2\%) could not be contacted because they could not be reached in spite of numerous personal visits $(45.7 \%)$, they had moved to an unknown address (33.9\%), the address was verifiably wrong (18.6\%), they were not able to participate due to a physical condition $(1.1 \%)$, or they lived in a closed institution $(0.7 \%)$. One woman was already deceased.

The remaining 5,203 women were located and eligible for the study. Of these, 2,138 women $(41.1 \%)$ did not respond. Reasons for nonresponse were refusal to take part $(68.3 \%)$, lack of time $(24.6 \%)$, and failure to appear at the interview $(7.2 \%)$. The remaining 3,065 women agreed to take part, resulting in a response rate of $58.9 \%$ at baseline. This response corresponds to $34.1 \%$ of the sampled population $(9,000)$ and $16.3 \%$ of the total population of women in Dresden aged 18-25 years $(18,830)$. Of the 3,065 respondents, 2,814 agreed to detailed participation (i.e., to complete the interview and/or the battery of self-report questionnaires), and 251 women filled in the short questionnaire. Regarding detailed participation, the following samples are available: 2,627 women completed the battery of questionnaires, 2,068 completed the diagnostic interview, and 1,881 both $[5,25]$.

\section{Follow-up investigation}

Only those 2,814 respondents who had agreed to detailed participation were available for the follow-up investigation. Of these, $26(0.9 \%)$ had explicitly declined further participation at baseline. The remaining 2,788 were approached for follow-up. Of those, 2,118 participated again in the follow-up investigation, resulting in a response rate of $76.0 \%$ relative to baseline participants. Reasons for dropout were relocation to an unknown address $(67.9 \%)$ and refusal to take part $(31.9 \%)$. One respondent had become permanently ill. Of the 2,118 follow-up respondents, 2,074 agreed to detailed participation, and 44 filled in the short questionnaire. Regarding detailed participation, the following samples are available: 2,018 women completed the battery of questionnaires, 1,538 completed the diagnostic interview, and 1,482 both. The number of respondents and response rates in the baseline and follow-up investigation are summarized in Fig. 2.

For 1,396 women, complete data (i.e., interview and battery of questionnaires) for both time points are available [59].

Sociodemographic characteristics of the sample

The baseline and follow-up sociodemographic characteristics of the 2,074 women who agreed to detailed participation at both time points are presented in Table 1. At baseline, the majority of the respondents $(59.8 \%)$ had completed the highest educational level of schooling that qualified them for university entry ("Abitur"). About 30\% of the respondents had attended intermediate level school ("Realschule" or "Polytechnische Oberschule") while a minority (2.8\%) had completed the lowest level of school education ("Hauptschule"). About half of respondents were unemployed (50.6\%) at baseline. About two-third of the participants had a partner $(65.0 \%)$ and were classified as being of middle socioeconomic status $(62.4 \%)$.

At the time of follow-up, more respondents had found a partner (70.3\%), had completed schooling (99.3\%), and were either in full- or part-time employment $(59.5 \%)$. With regard to the assessment of socioeconomic status it is important to note that respondents who were living with 
Fig. 2 Number of respondents and response rates at baseline and follow-up

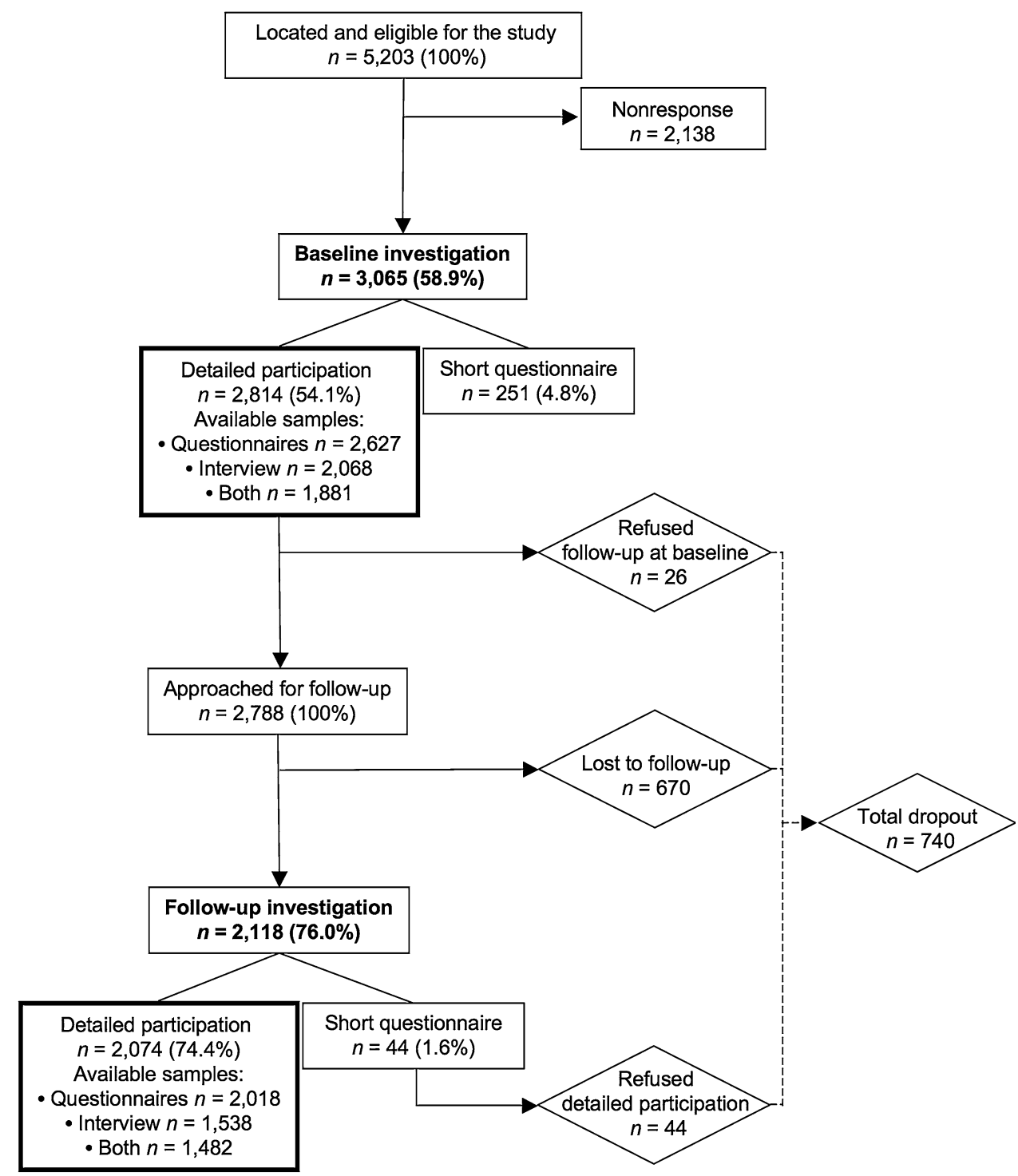

their parents were attributed their parents' status. The respondents' own socioeconomic status was assessed only if they were living in a separate household on their own. Thus, respondents who had left home during follow-up were usually assigned to a lower socioeconomic status than at baseline.

\section{Instruments}

\section{Diagnostic assessment: F-DIPS}

The diagnostic assessment was made by administering the "Diagnostisches Interview bei Psychischen StörungenForschungsversion" (F-DIPS; translation: Diagnostic Interview for Mental Disorders, Research Version) [44]. The F-DIPS is an earlier version of the DIPS [26, 54, 57] and is based on a German translation and extension of the
Anxiety Disorders Interview Schedule (ADIS-IV-L) [14]. It is a structured interview for the assessment of Axis I mental disorders according to DSM-IV [1].

The following disorders can be assessed with the FDIPS: all anxiety disorders, all affective disorders, the research diagnosis mixed anxiety-depression, somatoform disorders, substance abuse and dependence, bulimia, anorexia, and some childhood disorders (attention-deficit/ hyperactivity disorder, conduct disorder, oppositional defiant disorder, encopresis, enuresis, and separation anxiety disorder). Furthermore, there is a sociodemographic section, a screening for psychosis, a screening for general medical condition and medication, a short section on family history of mental disorders, and a section about treatment for mental disorders. Axis V (global assessment of functioning) is also rated. All diagnostic sections start with one or several stem questions that assess core symptoms of a mental disorder (corresponding to criterion A 
Table 1 Sociodemographic characteristics of the follow-up sample

\begin{tabular}{lll}
\hline Variable & \multicolumn{2}{l}{ Follow-up sample $^{\mathrm{d}}(n=2,074)$} \\
\cline { 2 - 3 } & At baseline (\%) & At follow-up (\%) \\
\hline Having a romantic partner & 65.0 & 70.3 \\
Highest educational level & & \\
No degree & & 0.7 \\
Mandatory basic $_{\text {Intermediate }}$ & 3.7 & 2.6 \\
Highest & 2.8 & 31.3 \\
Employment & 33.7 & 65.4 \\
Unemployed $^{\mathrm{b}}$ & 59.8 & \\
Part-time & & 40.5 \\
Full-time & 50.6 & 21.0 \\
Socioeconomic status & 16.4 & 38.5 \\
Low & 33.0 & \\
Middle & 29.9 & 33.8 \\
High & 62.4 & 59.5 \\
\hline
\end{tabular}

${ }^{a}$ Including those still at school

b Including students

c Working $\leq 34 \mathrm{~h}$ per week

d Women who agreed to detailed participation in both investigations

and/or B of DSM-IV disorders). If respondents answer affirmatively, they are then interviewed in detail to evaluate DSM-IV criteria. A diagnosis is assigned if all DSM-IV criteria for a disorder are satisfied. In the baseline investigation, each diagnosis was given for the past 7 days and lifetime. For the follow-up investigation, the F-DIPS was modified to assess each diagnosis for the past 7 days and the interval between the two investigations. The mean duration of the interviews at baseline was $114 \mathrm{~min}$ $(\mathrm{SD}=40 \mathrm{~min}, \quad$ range $=30-330 \mathrm{~min})$, and the mean duration of the interviews at follow-up was $77 \mathrm{~min}$ $(\mathrm{SD}=34 \mathrm{~min}$, range $=15-270 \mathrm{~min})$. The second interview was shorter than the first because it only diagnosed each disorder from the time since baseline. Moreover, there was no assessment of childhood disorders.

\section{Reliability and validity of the F-DIPS}

The retest reliability of the F-DIPS was tested in a sample of 191 psychosomatic patients [30]. The patients underwent two independent administrations of the F-DIPS within a mean test-retest interval of 2 weeks (range = 1-4 weeks). Diagnostic concordance was calculated by using Cohen's kappa $(\kappa)$ and Yule's $Y(\gamma)$ agreement coefficients. Good to very good kappa values were found for substance and eating disorders $(\kappa=0.70, \gamma=0.85$ and $\kappa=0.89, \gamma=0.94$, respectively). Kappa values were good for affective and somatoform disorders $(\kappa=0.71$, $\gamma=0.72$ and $\kappa=0.66, \gamma=0.72$, respectively). There was only fair agreement for anxiety disorders $(\kappa=0.64$, $\gamma=0.65)$.

In the same study, the validity of the F-DIPS was examined through comparison with self-report questionnaires and diagnoses made by therapists. F-DIPS diagnoses for anxiety, affective, and somatoform disorders showed fair agreement with diagnoses assigned by clinicians ( $\kappa=0.49, \kappa=0.43$, and $\kappa=0.47$, respectively). Substance disorders showed good agreement $(\kappa=0.66)$. For eating disorders, agreement was excellent $(\kappa=0.88)$. Overall, the study indicated that the F-DIPS proved to be a valid instrument for the diagnostic evaluation of mental disorders [30].

Summarizing from this study, the reliability of most F-DIPS diagnoses was comparable with other diagnostic interviews. Regarding validity, the F-DIPS was superior to standardized interviews, i.e., the Composite International Diagnostic Interview (CIDI) [62] and the Diagnostic Interview Schedule (DIS) [52], and comparable to the Structured Clinical Interview for DSM (SCID) [56]. For anxiety disorders, the F-DIPS had higher validity than the SCID [30].

\section{Questionnaires}

Respondents completed a battery of questionnaires assessing a broad range of potential predictors of anxiety disorders and depression. Types of predictors included psychopathology, cognitive factors, stress and coping, protective factors, and several additional psychosocial factors. An overview of the questionnaires used in the baseline and follow-up investigation is presented in Table 2. The majority of the questionnaires are standardized instruments with highly established psychometric properties.

For the evaluation of nonresponse bias, the DPS study team developed a 24-item short questionnaire containing the subscales anxiety (6 items from the Beck Anxiety Inventory, BAI) [3, 43]), depression (6 items from the revised Symptom Checklist-90, SCL-90-R, depression subscale), and somatization (12 items from the SCL-90-R somatization subscale) $[13,20])$. Each item was rated on a scale from 0 (not at all) to 3 (hardly bearable). Subscale scores were calculated as a simple sum of items within each subscale.

\section{Fieldwork}

Interviewers

Interviews at baseline were conducted by a total of 80 interviewers; interviews at follow-up by a total of 72 


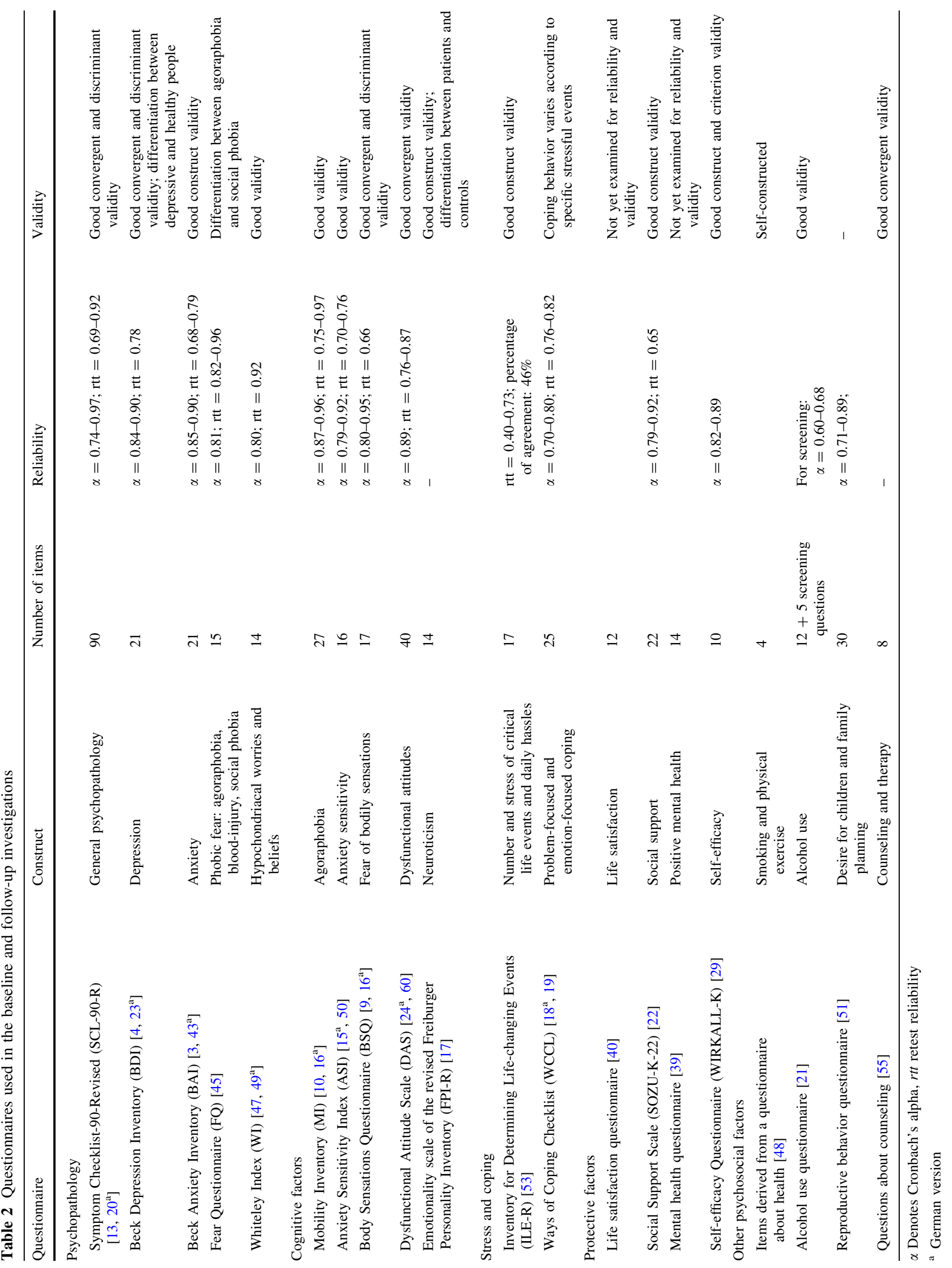


interviewers. Overall, 16 interviewers were involved in the fieldwork of both investigations. All interviewers were psychologists, physicians, or psychology students in their final year of study. On average, each interviewer conducted 20.2 interviews $(\mathrm{SD}=17.9)$. To ensure blinding, the interviewer who conducted the follow-up interview was unaware of the participant's diagnoses at baseline.

All interviewers underwent 1 week of intensive training focusing especially on the content of the DPS and the use of the F-DIPS. During training, supervisors explained the different disorders, emphasizing DSM-IV criteria and differential diagnoses. The interviewers practised all F-DIPS sections in a pre-field training and rated four videotaped interviews with patients. After training, each interviewer conducted two practice interviews before commencing fieldwork.

\section{Procedure}

All selected women received a letter of introduction and a maximum of three reminders asking them to take part in a study about mental health in Dresden. In addition, interviewers made up to ten phone calls or personal visits at different times of the day and week to establish contact with a woman. At baseline, no reimbursement for participation in the study could be offered. At follow-up, respondents received a small gift package funded by sponsorship. In addition, a limited number of telephone cards and cinema vouchers were offered to reluctant respondents as an incentive to participate for the second time at follow-up. Respondents of both investigations were sent a summary of the results of the DPS at the end of the study.

The interviewer invited the respondent for an individual face-to-face interview wherein the respondent could choose the location (Dresden University of Technology, the participant's home, or a neutral location such as a quiet café). The questionnaires were either filled out directly after the interview or completed at home and posted. In cases where respondents agreed to fill in questionnaires only, the battery of questionnaires was sent by post. All respondents provided informed consent. At the end of fieldwork, the short questionnaire was sent to all reluctant respondents who had not explicitly declined to take part in the study. Procedures at baseline and follow-up were identical.

All interviewers received biweekly supervision during fieldwork. Moreover, supervisors proofread every single completed interview protocol for formal consistency, appropriate recording, and coding. In cases where problems were detected, the interviewer was contacted and instructed for corrections.

\section{Evaluation of nonresponse and dropout}

Nonresponse bias in the baseline investigation

Selective nonresponse may affect the validity of the data. Therefore, the following checks on the representativeness of the DPS sample were made. First, we tried to determine if the DPS sample is representative of the total population with regard to educational level. Because the 1996 German Microcensus, the official statistical survey conducted by the Federal Statistical Office [37], contain a very small sample of 18- to 25-year-old women living in Dresden ( $n=180)$, a comparison with these population data turned out to be inappropriate. Therefore, we gathered data from the Saxon Statistical Office about how many 18- to 25year-old women living in Dresden were enrolled in one of the Dresden higher education institutions (i.e., university or college). In winter term 1996/97, 7,989 of the Dresden women aged 18-25 were enrolled in a Dresden institution of higher education. Accordingly, these women must have been required to have successfully completed their higher education entrance qualification (i.e., the highest educational level of schooling in Germany). Given that in 1996 about 18,830 women in the target age range were living in Dresden, it can be assumed that at least $42.4 \%$ of them $(n=7,989)$ had completed the highest educational level. Therefore, assuming that not all of the women with higher education entrance qualification were actually enrolled in higher education $(28.3 \%$ of the 1996 graduates with higher education entrance qualification entered apprenticeship [27]), the high proportion of highly educated women in the DPS sample (about 60.0\%) can be regarded as representative for Dresden. In this context, it should be noted that Dresden being a city with several large universities is an important center of learning in Saxony and the high density of nonworking young adults with the highest educational level is rather typical of Dresden.

Second, we compared respondents with the 251 initial nonrespondents who refused detailed participation in the DPS but completed the short questionnaire. The anxiety, depression, and somatization subscale scores of the shortquestionnaire respondents were compared with the subscale scores of the 2,627 respondents who completed the battery of questionnaires. Effect sizes comparing the two groups were calculated for each subscale using Cohen's $d$ [11]. The mean subscale scores of the two groups along with effect sizes are shown in Table 3. The 251 shortquestionnaire respondents had significantly higher anxiety, depression, and somatization scores compared to respondents who completed the series of questionnaires. Thus, the analyses of response bias suggested that women with more mental problems were less likely to participate in the study. 
Table 3 Association between mental problems and nonresponse based on a comparison of respondents completing short questionnaire vs. respondents completing questionnaires

\begin{tabular}{|c|c|c|c|c|c|}
\hline Subscale & Possible range & $\begin{array}{l}\text { Screening questionnaire } \\
(n=251) \\
M(\mathrm{SD})\end{array}$ & $\begin{array}{l}\text { Questionnaires } \\
(n=2,627) \\
M(\mathrm{SD})\end{array}$ & Cohen's $d$ & $t$ \\
\hline Anxiety & $0-18$ & $3.17(2.87)$ & $1.33(2.05)$ & 0.73 & $13.15 * * *$ \\
\hline Depression & $0-18$ & $4.37(3.85)$ & $2.95(3.24)$ & 0.40 & $6.62 * * *$ \\
\hline Somatization & $0-36$ & $7.10(4.35)$ & $4.45(4.30)$ & 0.63 & $9.46 * * *$ \\
\hline
\end{tabular}

Cohen's $d$ : 0.2 indicates a small effect size, 0.5 a medium effect size, and 0.8 a large effect size *** $P<0.001$

Effect sizes for mental problems between respondents and initial nonrespondents were about medium.

\section{Dropout}

Dropout or attrition at follow-up may lead to systematic bias in the results of the study. To evaluate the degree to which the follow-up sample $(n=2,074)$ might have become biased, we compared follow-up respondents with those who dropped out $(n=740)$ on sociodemographic characteristics at baseline. Odds ratios (ORs) and 95\% confidence intervals (CIs) for dropout at follow-up were calculated, comparing the dropout group with the response group. Ordinal scores were modeled as continuous variables using logistic regression models. Results are depicted in Table 4. Dropout in the follow-up investigation was significantly associated with having a romantic partner, having a higher level of employment, having a lower educational level, and having a lower socioeconomic status.

We also investigated whether dropout was related to point or lifetime diagnoses of mental disorders at baseline. Dropouts were significantly more likely to have a point $(\mathrm{OR}=2.85,95 \% \mathrm{CI}=1.17-6.93, P<0.05)$ or lifetime diagnosis $(\mathrm{OR}=2.02,95 \% \mathrm{CI}=1.11-3.68, P<0.05)$ of any somatoform disorder at baseline. It is important to note that for all other mental disorders the differences between the two groups were not significant.

\section{Strengths and limitations of the study design}

The DPS was basically designed in order to improve overall knowledge of anxiety disorders and depression in young women. The DPS is the first prospective epidemiological study of mental disorders that has been carried out in former East Germany. It is also the first study that has investigated a broad spectrum of potential predictors of mental disorders in such a large sample of women during the peak period for first onset of anxiety disorders and depression.
Analyses of nonresponse bias at baseline indicated that women who refused to complete the interview and the battery of questionnaires had higher anxiety, depression, and somatization scores than those who agreed to. There are at least two possible explanations for these findings. First, it might be possible that the prevalence and incidence rates of mental disorders in the population of young women from the former Dresden area are even higher than the rates obtained in the DPS. Further analyses of these data suggest a second explanation. Stratification by mode of assessment revealed that women who completed both interview and questionnaires reported lower scores than those who completed the battery of questionnaires only. Also, women who only completed the battery of questionnaires reported lower scores than short-questionnaire respondents (data are available on request from the first author). Thus, it might be that comprehensiveness and degree of detail of the different modes of assessment have affected the response behavior of the women.

In line with other epidemiological studies [12], dropout analyses indicated that dropout at follow-up was associated with certain sociodemographic characteristics of the respondents (i.e., lower education and lower socioeconomic status). Notably, however, except for the loss of a disproportionately large number of respondents with somatoform disorders, there were no differences between the baseline and the follow-up sample with regard to key measures of mental disorders. Accordingly, bias introduced by dropout at follow-up was minor. Because no corrections for multiple testing were made, the problem of falsepositive findings may be a point of concern in these analyses.

With respect to limitations of the study, the following issues have to be considered. First, a large number of women $(42.2 \%)$ selected from the registers of residents could not be contacted. In Germany, the registers of the registry office can usually be regarded as accurate because of regular updates and strict legal enforcement. However, at the time of the baseline assessment, Dresden was undergoing massive constructional and political changes related to the German reunification in 1990, which resulted 
Table 4 Baseline sociodemographic characteristics as predictors of dropout at follow-up

Some percentages do not total 100 due to rounding

$O R$ odds ratio from logistic regression, $\mathrm{CI}$ confidence interval

*** $P<0.001$

${ }^{\text {a }}$ Ordinal variable that was modeled as a continuous variable

b Including those still at school

${ }^{c}$ Including students

${ }^{\mathrm{d}}$ Working $\leq 34 \mathrm{~h}$ per week

\begin{tabular}{|c|c|c|c|}
\hline \multirow[t]{2}{*}{ Baseline sociodemographics } & \multicolumn{2}{|l|}{ Detailed participation at baseline } & \multirow[t]{2}{*}{ OR $(95 \% \mathrm{CI})$} \\
\hline & $\begin{array}{l}\text { Detailed participation } \\
\text { at follow-up }(n=2,074)(\%)\end{array}$ & $\begin{array}{l}\text { Dropout at follow-up } \\
(n=740)(\%)\end{array}$ & \\
\hline Having a romantic partner & 65.0 & 75.1 & $1.63 * * *(1.34-1.98)$ \\
\hline \multicolumn{4}{|l|}{ Highest educational level $^{\mathrm{a}}$} \\
\hline No degree ${ }^{b}$ & 3.7 & 2.9 & $0.70 * * *(0.62-0.78)$ \\
\hline Mandatory basic & 2.8 & 5.9 & \\
\hline Intermediate & 33.7 & 50.1 & \\
\hline Highest & 59.8 & 41.0 & \\
\hline \multicolumn{4}{|l|}{ Employment $^{\mathrm{a}}$} \\
\hline Unemployed $^{\mathrm{c}}$ & 50.6 & 43.2 & $1.27 * * *(1.15-1.39)$ \\
\hline Part-time $^{\mathrm{d}}$ & 16.4 & 11.5 & \\
\hline Full-time & 33.0 & 45.3 & \\
\hline \multicolumn{4}{|l|}{ Socioeconomic status ${ }^{\mathrm{a}}$} \\
\hline Low & 29.9 & 44.4 & $0.62 * * *(0.53-0.73)$ \\
\hline Medium & 62.4 & 49.3 & \\
\hline High & 7.7 & 6.3 & \\
\hline
\end{tabular}

A third point of discussion relates to the age range of the DPS study population. Retrospective studies have suggested an even earlier age range of first onset than the age range chosen for the DPS. This might be due to the fact that retrospective studies, which are also more likely to be affected by recall bias, usually assess the onset of the first symptoms of a disorder and not its full-blown emergence. Therefore, it should be stressed that the incidence measures of the DPS capture the actual onset of DSM-IV disorders, e.g., the time when symptoms are so strong that they meet full DSM-IV criteria. In this regard, a more general notion of caution concerns the retrospective nature of diagnoses despite the overall prospective-longitudinal design of the DPS study. The assessment of disorders at baseline was retrospective, and therefore might be influenced by recall bias, especially as the DPS consists of one follow-up investigation only.

A fourth limitation is the restriction of the DPS sample to female gender and a quite narrow age range of participants. Furthermore, it is possible that findings from this urban sample, which consisted of well-educated young women with a predominately higher socioeconomic status, may not generalize to other populations or regions.

Fifth, our relatively short follow-up period of 17 months can be viewed as a limitation because it may fail to cover the whole risk period for first onset of anxiety disorders and depression. However, the longer the followup period is, probably incident cases are more likely to be affected by recall bias. Given that the DPS studied women during the high-risk period of young adulthood, a relatively short follow-up can be viewed as adequate. Also, expanded follow-up periods may lead to higher attrition rates. For future studies, it is recommended to consider mistrust regarding recordings of personal data [41]. 
a long-term follow-up with multiple waves of data collection.

Finally, although F-DIPS diagnostic interview in this version has only been used for this study and the study of psychometric properties are just part of a dissertation, it is based on a well-established interview, the ADIS-IV-L [14], with good psychometric properties. Furthermore, note that its updated version, the DIPS, that is largely based on the F-DIPS shows good reliability and validity [26, 57].

The study design chosen for the DPS also has a number of advantages. The DPS describes the prevalence of anxiety disorders, depression, and other mental disorders in a large sample of women during the transition from adolescence into early adulthood. In contrast to clinical samples, the DPS offers a more accurate estimation of the prevalence of these disorders in the general population. Moreover, the prospective design allows studying the incidence, course, and remission of mental disorders. With regard to the quality of the data, it should be emphasized that the diagnostic assessment was based on structured interviews conducted by highly trained interviewers. All interviewers were closely monitored throughout the fieldwork to assure high quality of administration.

The sample composition of the DPS can be viewed as a strong feature of the study. By using a sample of women in this developmental phase, we were able to investigate a high-risk age period for first onset of mental disorders. We were also able to examine predictors with less concern for the confounding effects of age, gender, and socioeconomic status, which could likely be problematic in a more diverse sample. With respect to gender, prior results have suggested that women are more likely to develop anxiety disorders and depression than men and therefore, patterns of incidence and predictors may be different in young men [6]. With regard to predictors, one may assume that the etiologic processes of mental disorders are comparable across different geographical areas and time contexts.

The design of the DPS has the special feature of assessing information about mental disorders and predictors with a combination of comprehensive categorical and dimensional assessments. The baseline and follow-up assessments include a broad range of questionnaires to record a variety of psychological, cognitive-behavioral, and socio-environmental factors that are assumed to be involved in anxiety disorders and depression. Types of factors assessed with questionnaires include protective factors, coping behavior, cognitive factors, critical life events and stress, and general health behavior. Many of these dimensional measures are based on standardized instruments with highly established psychometric properties. The diagnostic assessment included information about participants' diagnoses, medication, treatment, and familial psychopathology. The DPS is the first prospective epidemiological study providing information about such a broad spectrum of disorder-related information from categorical and dimensional assessments. The design of the DPS offers the basis for studying these factors prospectively as potential predictors of the incidence and remission of anxiety disorders and depression. Detailed examination of these predictors might provide novel insights into the etiologic processes of these disorders. The large number of women suffering from anxiety disorders and depression could profit from such insights through the improvement of intervention and prevention.

Acknowledgments This study was supported by grant DLR 01EG9410 from the German Ministry of Science, Research and Education. Jürgen Margraf and Julia Trumpf were supported by grant 51A240-104890 from the Swiss National Science Foundation. We would like to thank the many people who contributed to the study.

\section{References}

1. American Psychiatric Association (1994) Diagnostic and statistical manual of mental disorders, 4th edn. APA, Washington DC

2. Baumeister H, Härter M (2007) Prevalence of mental disorders based on general population surveys. Soc Psychiatry Psychiatr Epidemiol 42:537-546

3. Beck AT, Epstein N, Brown G, Steer RA (1988) An inventory for measuring clinical anxiety: psychometric properties. J Consult Clin Psychol 56:893-897

4. Beck A, Ward C, Mendelsohn M, Mock J, Erbaugh J (1961) An inventory for measuring depression. Arch Gen Psychiatry 4:561571

5. Becker ES, Türke V, Neumer S, Margraf J (2000) Incidence and prevalence rates of mental disorders in a community sample of young women: results of the Dresden study. In: Manz R, Kirch W (eds) Public health research and practice: report of the public health research association Saxony. Roderer, Regensburg, pp 259-291

6. Bijl RV, de Graaf R, Ravelli A, Smit F, Vollebergh WAM (2002) Gender and age-specific first incidence of DSM-III-R psychiatric disorders in the general population. Soc Psychiatry Psychiatr Epidemiol 37:372-379

7. Bijl RV, Ravelli A, van Zessen G (1998) Prevalence of psychiatric disorder in the general population: results of the Netherlands Mental Health Survey and Incidence Study (NEMESIS). Soc Psychiatry Psychiatr Epidemiol 33:587-595

8. Bittner A (2006) Gemeinsamkeiten und Unterschiede von Vulnerabilitäts- und Risikofaktoren bei Angststörungen und Depression: Eine epidemiologische Studie. Unpublished dissertation, Dresden University of Technology

9. Chambless DL, Caputo GC, Bright P, Gallagher R (1984) Assessment of fear in agoraphobics: the body sensations questionnaire and the agoraphobic cognitions questionnaire. J Consult Clin Psychol 52:1090-1097

10. Chambless DL, Caputo GC, Jason SE, Graceley EJ, Williams C (1985) The mobility inventory for agoraphobia. Behav Res Ther 23:35-44

11. Cohen J (1997) Statistical power analysis for the behavioral sciences. Academic, New York

12. de Graaf R, Bijl RV, Smit F, Ravelli A, Vollebergh WAM (2000) Psychiatric and sociodemographic predictors of attrition in a longitudinal study: The Netherlands Mental Health Survey and Incidence Study (NEMESIS). Am J Epidemiol 152:1039-1047 
13. Derogatis LR (1977) The SCL-90R administration, scoring, and procedures. Clinical Psychometric Research, Baltimore

14. Di Nardo PA, Brown TA, Barlow DH (1995) Anxiety Disorders Interview Schedule for DSM-IV: lifetime version (ADIS-IV-L). Graywind Publications, Albany

15. Ehlers A (1986) Angst-Sensitivitäts-Index. Unpublished manuscript

16. Ehlers A, Margraf J, Chambless DL (1993) Fragebogen zu körperbezogenen Ängsten, Kognitionen und Vermeidung, Beltz, Weinheim

17. Fahrenberg J, Hampel R, Selgl H (1989) Das Freiburger Persönlichkeitsinventar FPI: Revidierte Fassung FPI-R. Hogrefe, Göttingen

18. Ferring D, Filipp SH (1989) Bewältigung kritischer Lebensereignisse: Erste Erfahrungen mit einer deutschsprachigen Version der "Ways of Coping Checklist. Z Differentielle Diagnostische Psychol 10:189-199

19. Folkman S, Lazarus RS (1980) An analysis of coping in a middleaged community sample. J Health Soc Behav 21:219-239

20. Franke GH (1995) Die Symptom Checkliste von Derogatis. Beltz, Göttingen

21. Frick U, Rehm J, Thien U, Spuhler T (1996) Zur Konstruktion und Validierung eines Indikators für Alkoholprobleme in der schweizerischen Gesundheitsbefragung. Soz Praventivmed 41:133-142

22. Fydrich T, Sommer G, Menzel U, Höll B (1987) Fragebogen zur sozialen Unterstützung (Kurzform; SOZU-K-22). Z Klin Psychol $16: 434-436$

23. Hautzinger M, Bailer M, Worall H, Keller F (1994) BeckDepressions-Inventar (BDI). Bearbeitung der deutschen Ausgabe, Testhandbuch. Huber, Bern

24. Hautzinger M, Luka U, Trautmann RD (1985) Skala dysfunktionaler Einstellungen-Eine deutsche Version der Dsyfunctional Attitude Scale. Diagnostica 31:312-323

25. Hoyer J, Becker ES, Neumer S, Soeder U, Margraf J (2002) Screening for anxiety in an epidemiological sample: predictive accuracy of questionnaires. J Anxiety Disord 16:113-134

26. In-Albon T, Suppiger A, Schlup B, Wendler S, Margraf J, Schneider S (2008) Validität des Diagnostischen Interviews bei Psychischen Störungen (DIPS für DSM-IV-TR). Z Klin Psychol Psychother 37:33-42

27. Institut der deutschen Wirtschaft (ed) (2007) Die Lehre lockt. Informationsdienst des Instituts der deutschen Wirtschaft Köln 22:1

28. Jacobi F, Wittchen H-U, Hölting C, Höfler M, Pfister H, Müller N et al (2004) Prevalence, co-morbiidty and correlates of mental disorders in the general population: results from the German Health Interview and Examination Survey (GHS). Psychol Med 34:597-611

29. Jerusalem M, Schwarzer R (1986) Fragebogen zur Erfassung von Selbstwirksamkeit. In: Schwarzer $\mathrm{R}$ (ed) Skalen zur Befindlichkeit und Persönlichkeit (Forschungsbericht 5). Free University of Berlin

30. Keller A (2000) Die Klassifikation psychischer Störungen nach DSM-IV mit Hilfe eines strukturierten diagnostischen Interviews (F-DIPS). Unpublished dissertation, Ruprecht Karls University of Heidelberg

31. Kessler RC, Berglund P, Chiu WT, Demler O, Heeringa S, Hiripi E et al (2004) The US National Comorbidity Survey Replication (NCS-R): design and field procedures. Int J Methods Psychiatr Res 13:69-92

32. Kessler RC, Berglund P, Demler O, Jin R, Merikangas KR, Walters EE (2005) Lifetime prevalence and age-of-onset distributions of DSM-IV disorders in the National Comorbidity Survey Replication. Arch Gen Psychiatry 62:593-602

33. Kessler RC, McGonagle KA, Zhao S, Nelson CB, Hughes M, Eshleman S et al (1994) Lifetime and 12-month-prevalence of
DSM-III-R psychiatric disorders in the United States: results from the National Comorbidity Survey. Arch Gen Psychiatry 51:8-19

34. Koch A, Gabler S, Braun M (1994) Konzeption und Durchführung der "Allgemeinen Bevölkerungsumfrage der Sozialwissenschaften” (ALLBUS). ZUMA-Arbeitsbereicht 94/11. Mannheim, ZUMA

35. Kraemer HC (2003) Current concepts of risk in psychiatric disorders. Curr Opin Psychiatry 16:421-430

36. Kraemer HC, Kazdin AE, Offord DR, Kessler RC, Jensen PS, Kupfer DJ (1997) Coming to terms with the terms of risk. Arch Gen Psychiatry 54:337-343

37. Lechert Y, Schmidt S (2000) Mikrozensus 1996: Dokumentation und Datenaufbereitung. ZUMA-Technischer Bericht 2000/07. Mannheim, ZUMA

38. Lewinsohn PM, Hyman H, Roberts RE, Seeley JR, Andrews JA (1993) Adolescent psychopathology: I. Prevalence and incidence of depression and other DSM-III-R disorders in high school students. J Abnorm Psychol 102:133-144

39. Lutz R, Heyn C, Schmid S, Sick U, Steinl B (1992) Fragebogen zur seelischen Gesundheit, Skala der Marburger Gesundheitsstudie I (alte Fassung). Unpublished manuscript

40. Lutz R, Heyn C, Schmid S, Sick U, Steinl B (1992) Fragebogen zur Lebenszufriedenheit, Skala der Marburger Gesundheitsstudie I (alte Fassung). Unpublished manuscript

41. Maercker A, Herrle J (2003) Long-term effects of the Dresden Bombing: relationships to control beliefs, religious beliefs, and personal growth. J Trauma Stress 16:579-587

42. Margraf J, Becker ES (1995) Prädiktoren psychischer Gesundheit bzw. Krankheit beim Übergang von der Jugend zum Erwachsenenalter in den neuen Bundesländern. In: Kirch W, Margraf J (eds) Public Health Forschungsverbund Sachsen. Gustav-Fischer, Stuttgart, pp 65-75

43. Margraf J, Ehlers A (2002) Beck Angstinventar. Deutsche Version (BAI). Testhandbuch. Hogrefe, Göttingen

44. Margraf J, Schneider S, Soeder U, Becker ES (1996) F-DIPS: Diagnostisches Interview bei Psychischen Störungen (Forschungsversion). Unpublished manuscript, Dresden University of Technology

45. Marks IM, Mathews AM (1979) Brief standard self-rating for phobic patients. Behav Res Ther 17:263-267

46. Offord DR, Boyle MH, Campbell D, Goering P, Lin E, Wong M et al (1996) One-year prevalence of psychiatric disorder in Ontarians 15 to 64 years of age. Can J Psychiatry 41:559-563

47. Pilowsky I (1967) Dimensions of hypochondriasis. Br J Psychiatry $113: 39-43$

48. Fragebogen zum Thema Gesundheit (n.d.) Unpublished manuscript. University of Zurich

49. Rief W, Hiller W, Geissner E, Fichter MM (1994) Hypochondrie: Erfassung und erste klinische Ergebnisse. Z Klin Psychol 23:34-42

50. Reiss S, Peterson RA, Gursky DM, McNally RJ (1986) Anxiety sensitivity, anxiety frequency and the prediction of fearfulness. Behav Res Ther 24:1-8

51. Richter Y, Unger U, Brähler E (1995) Der Leipziger Fragebogen zum Reproduktionsverhalten-Zu Aspekten des Reproduktionsverhaltens in den neuen Bundesländern. Unpublished manuscript

52. Robins LN, Helzer JE, Croughan J, Ratcliff KS (1981) National Institute of Mental Health Diagnostic Interview Schedule. Its history, characteristics, and validity. Arch Gen Psychiatry 38:381-389

53. Siegrist J, Dittmann KH (1983) Inventar zur Erfassung lebensverändernder Ereignisse (ILE). ZUMA—Handbuch sozialwissenschaftlicher Skalen. Informationszentrum Sozialwissenschaften, Bonn

54. Schneider S, Margraf J (2006) DIPS: Diagnostisches Interview bei psychischen Störungen. Springer, Berlin 
55. Soeder U (1995) Die Prävalenz von psychosozialen Beschwerden bei Heidelberger Studierenden. Unpublished diploma-thesis, University of Heidelberg

56. Spitzer LR, Williams JBW, Gibbon M, First MB (1992) The Structured Clinical Interview for DSM-II-R (SCID) I: history, rationale, and description. Arch Gen Psychiatry 49:624-629

57. Suppiger A, In-Albon T, Herren C, Bader K, Schneider S, Margraf J (2008) Reliabilität des Diagnostischen Interviews bei Psychischen Störungen (DIPS für DSM-IV-TR) unter klinischen Routinebedingungen. Verhaltensther 18:237-244

58. State capital Dresden, communal statistical office (1996) Dresden in Zahlen 1996: statistische Informationen. Communal statistical office, Dresden
59. Vriends N, Becker ES, Meyer A, Williams SL, Lutz R, Margraf J (2007) Recovery from social phobia in the community and its predictors: data from a longitudinal study. J Anxiety Disord 21:320-337

60. Weissman AN, Beck A (1978) Development and validation of the Dysfunctional Attitude Scale: a preliminary investigation. Paper presented at the annual meeting of the Association for the Advancement of Behavior Therapy, Chicago

61. Wittchen HU, Nelson CB, Lachner G (1998) Prevalence of mental disorders and psychosocial impairments in adolescents and young adults. Psychol Med 28:109-126

62. World Health Organization (1997) Composite international diagnostic interview. Version 2.1. World Health Organization, Geneva 